Article

\title{
Numerical Study of the Strength and Characteristics of Sandstone Samples with Combined Double Hole and Double Fissure Defects
}

\author{
Junbiao Ma ${ }^{1}$, Ning Jiang ${ }^{1, *}$, Xujun Wang ${ }^{2}$, Xiaodong Jia ${ }^{2}$ and Dehao Yao ${ }^{1}$ \\ 1 State Key Laboratory of Mine Disaster Prevention and Control, Shandong University of Science and \\ Technology, Qingdao 266590, China; 18135836658@163.com (J.M.); dehaoyao@163.com (D.Y.) \\ 2 Jining No.3 Coal Mine, Yanzhou Coal Mining Company Limited, Jining 272100, China; \\ cumtckwxj@126.com (X.W.); jxd0303@163.com (X.J.) \\ * Correspondence: jiangning@sdust.edu.cn; Tel.: +86-137-9199-1151
}

check for

updates

Citation: Ma, J.; Jiang, N.; Wang, X.; Jia, X.; Yao, D. Numerical Study of the Strength and Characteristics of Sandstone Samples with Combined Double Hole and Double Fissure Defects. Sustainability 2021, 13, 7090. https://doi.org/10.3390/su13137090

Academic Editors: Bin Gong,

Yu Zhang, Lianzhen Zhang and Guoming Liu

Received: 27 May 2021

Accepted: 22 June 2021

Published: 24 June 2021

Publisher's Note: MDPI stays neutral with regard to jurisdictional claims in published maps and institutional affiliations.

Copyright: (c) 2021 by the authors. Licensee MDPI, Basel, Switzerland. This article is an open access article distributed under the terms and conditions of the Creative Commons Attribution (CC BY) license (https:/ / creativecommons.org/licenses/by/ $4.0 /)$.

\begin{abstract}
To explore the failure mechanism of rock with holes and fissures, uniaxial compression tests of sandstone samples with combined double hole and double fissure defects were carried out using Particle Flow Code 2D (PFC2D) numerical simulation software. The failure behaviour and mechanical properties of the sandstone samples with combined double hole and double fissure defects at different angles were analysed, and the evolution results of the stress field and crack propagation were studied. The results show that with a decrease in fissure angle, the crack initiation stress, damage stress, elastic modulus and peak stress of the defective rock decrease, while the peak strain increases, and the brittleness of the rock is weakened. Rocks with combined double hole and double fissure defects at different angles lead to different failure modes, crack initiation positions and crack development directions. After uniaxial compression, both compressive stress and tensile stress concentration areas are produced in the defective rock, but the compressive stress concentration is of primary importance. The concentration area is mainly distributed around the holes and fissures and the defect connecting line, and the stress concentration area decreases with the decreasing fissure angle. This study can correctly predict the mechanical properties of rock with combined double hole and double fissure defects at different angles and provide a reference for actual rock engineering.
\end{abstract}

Keywords: PFC2D; uniaxial compression; failure modes; evolution results of the stress field; crack propagation

\section{Introduction}

Under the influence of geological tectonism, a large number of holes and fissures are formed in the strata and in coal seams. The mechanical behaviour and failure law of coal and rock largely depend on the distribution and development degree of holes and fissures in the coal or rock [1-6]. In dams, tunnels and other rock engineering projects, the failure and instability of rock masses are usually caused by the opening, closing, expanding and connecting of internal defects. Holes and fissures are the most basic rock defects [7-13]. The different distributions of defects make the strength characteristics, deformation and failure law of rock more complex [14-20]. Therefore, it is of great engineering significance to study the strength, deformation and failure law of prefabricated defective rock that has a combination of holes and fissures to ensure the stability of rock engineering.

At present, many scholars have researched prefabricated defective rock using indoor experiments and numerical simulations. The research has included the distribution characteristics, length, location and quantity of holes and fissures. The mechanical failure mode and crack propagation process of rock at different defects have been studied [21,22]. Among these studies, there have been many achievements in single defect research. Chen et al. [23] studied a rock-like material which contained prefabricated parallel double fissures, studying how the fissures length difference and spacing influence the failure of specimens under 
uniaxial compression, and analysing them with fracture mechanics theory. Chen et al. [24] studied the failure behaviour and mechanical properties of rock samples with holes of various shapes using the finite element method, determined four failure modes, and studied the crack propagation and the evolution of the stress field. Wang et al. [25] carried out uniaxial compression experiments on granite specimens under four different filling states and studied the effects of different filling materials on the strength, fracture behaviour and strain state of defective rock specimens. The results showed that the filling material can reduce the tip stress. Wang [26] studied the crack interaction, initiation and propagation of rock-like materials with two collinear fissures. The results showed that with the growth of wing cracks, the stress intensity factor of wing cracks first decreases and then tends to be stable. Zeng [27] studied the mechanical properties and fracture behaviour of specimens with holes under uniaxial compression loading, carried out the corresponding numerical simulation using PFC2D, and obtained the stress field distribution before and during fracture. To study the influence of the arc angle on the mechanical behaviour, failure mode and fracture evolution process of sandstone, Zhu [28] carried out numerical simulations of arc fractured sandstone samples at different angles. The results showed that with increasing arc angle, the peak strength and strain of sandstone samples first decrease and then increase. Huang [29] conducted uniaxial compression tests on granite specimens with three noncoplanar cavities and analysed the relationship between the stress, the acoustic emission (AE) and the crack evolution process. The change in the field and displacement field of the defective granite specimen was simulated using PFC2D and revealed the evolution mechanism of fissures around holes in the granite specimen. Yang [30] carried out a series of laboratory tests and numerical simulations on rock-like material samples with two nonparallel fissures, analysed the mechanical parameters of the prefabricated defect specimens under different loading rates, and revealed the macro mechanical behaviour and micro mechanism of prefabricated crack specimens.

In the research of composite defect rock, Chen et al. [31] carried the uniaxial compression experiments on the sandstone samples containing double fissures and a single circular hole were carried out by using electro-hydraulic servo universal testing machine to investigate the effect of rock bridge angle $\beta$ and fissure angle $\alpha$ on mechanical properties and evolution characteristics of cracks. Liu [32] studied the strength and fracture mechanism of sandstone specimens with defects using numerical simulations of samples with elliptical holes and cracks, obtained the evolution law of the strain difference, and pointed out that the ligament angle is an important factor affecting the strength and deformation of the sandstone specimens. Yin [33] studied the influence of the defect geometry on the mechanical behaviour and crack merging mode of sandstone specimens with different fissure angles and different fissure lengths under uniaxial compression. The numerical simulation of sandstone specimens with defects was carried out using RFPA2D, and crack propagation and initiation were studied.

The research on prefabricated defects by these scholars only considered a simple defect specimen or a simple superposition of different defects, but there has been less research on the mechanical characteristics and failure process of complex defects. In actual rock engineering, most rock defects are complex combined defects, and these combined defects determine the mechanical properties and structural stability of the rock. Therefore, in this paper, a defective specimen with combined double holes and double fissures defects is used as the study sample. At the same time, there are some problems in the process of laboratory testing, such as the difficulty of preparing rock, the discrete influence of the rock, and the difficulty of observing the rock's internal failure. Therefore, in this study, the mechanical behaviour, failure characteristics, stress evolution law, crack propagation path and other aspects of sandstone samples with combined double hole and double fissure defects are simulated by PFC2D. 


\section{Model Establishment and Parameter Selection}

\subsection{Selection of Micro Parameters}

\subsubsection{Particle Flow Code}

As a kind of discrete element simulation software, particle flow code PFC2D is a new numerical simulation technology. Its theoretical basis is the discrete element method proposed by Cundall [34] and is used for dynamic mechanical analysis of granular materials, such as the stability, deformation and constitutive relationship of granular solids. PFC2D uses isotropic (or anisotropic) discrete elements to simulate the motion and interaction of granular media. The position and velocity of particles at each moment are determined by the translational and rotational motion equations in the plane. As a tool to study the characteristics of granular media, it uses several hundred to tens of thousands of representative granular elements to obtain the constitutive model of granular media through numerical simulation experiments.

In the numerical simulation software PFC2D, contact and parallel connections can be used to simulate the connections between rock particles. Contact connections can only transfer forces between elements, and parallel connections can not only transfer forces but can also transfer torques $[35,36]$, as shown in Figure 1. Parallel bonds are regarded as a group of springs that work together with the contact between particles. When the particles are bonded, they can resist torque and show linear elasticity until the force exceeds its strength limit, at which point the bonding model is destroyed.

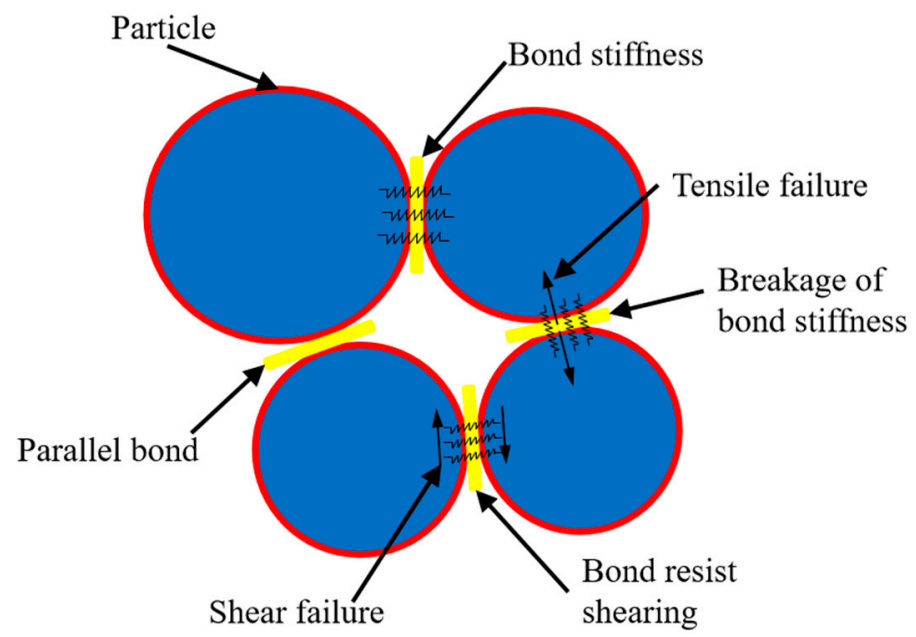

Figure 1. Mechanical mechanism of the parallel bond model.

\subsubsection{Determination of Microscopic Parameters}

A set of micro mechanical parameters needs to be determined to simulate rock samples for the particle flow code (PFC2D) software. However, these mechanical parameters cannot be obtained directly from laboratory tests. Therefore, it is necessary to select and verify the micro parameters before numerical simulation. Then, the numerical simulation results are compared with the experimental results. The micro mechanical parameters of particles are repeatedly adjusted by the "trial and error method [37]" until they meet the requirements of simulation analysis.

It is worth noting that References $[38,39]$ used the method of particle deletion to prefabricate cracks, but in the micro parameter calibration, only the macro parameter matching of complete rock specimens was used for calibration. The results show that the material mechanical properties of the prefabricated, defective rock formed by deleting the micro particles are completely determined by the micro material properties of the rock and the geometric shape of the fracture, and there is no need to calibrate the corresponding micro parameters of the fracture specimen. Therefore, the complete rock sample is used to calibrate the micro parameters of the numerical specimen. 
Table 1 lists the microscopic parameters used in the numerical simulation model in this study. Table 2 shows the experimental and numerical mechanical parameters for the complete specimen. In addition, Figure 2 shows a comparison of the stress-strain curves and failure modes of the complete specimen in both the experimental and numerical simulations under uniaxial compression. Figure 2 shows that the stress-strain curve and failure mode are in good agreement between the numerical results and the experimental results. The results in Table 2 and Figure 2 show the correctness of the selection of the microscopic parameters in Table 1, and the microscopic parameters can be used in the simulation experiments of rock specimens with combined double hole and double fissure defects at different angles.

Table 1. The micro parameters used in the PFC2D model.

\begin{tabular}{cccc}
\hline Parameter & Value & Parameter & Value \\
\hline Porosity, $e$ & 0.1 & Minimum particle diameter, $r_{\min }$ & 0.2 \\
Parallel bond cohesive force, $F_{c}(\mathrm{MPa})$ & 22 & Particle density, $\rho\left(\mathrm{kg} / \mathrm{m}^{3}\right)$ & 2500 \\
Particle size ratio, $s$ & 1.4 & Particle contact modulus, $E_{\mathrm{p}}(\mathrm{GPa})$ & 2.5 \\
Parallel bond tensile strength, $F_{t}(\mathrm{MPa})$ & 15 & Friction angle of parallel bond, $\theta\left({ }^{\circ}\right)$ & 50 \\
\hline
\end{tabular}

Table 2. Comparison between the experimental and numerical mechanical parameters of the intact specimen.

\begin{tabular}{cccc}
\hline & Elastic Modulus, $\boldsymbol{E i}(\mathrm{GPa})$ & Peak Strength, $\sigma_{\max }(\mathbf{M P a})$ & Poisson's Ratio, $\boldsymbol{v}$ \\
\hline Experimental results & 6.24 & 52.93 & 0.14 \\
Numerical results & 6.28 & 57.16 & 0.16 \\
Relative difference & 0.04 & 4.23 & 0.02 \\
\hline
\end{tabular}

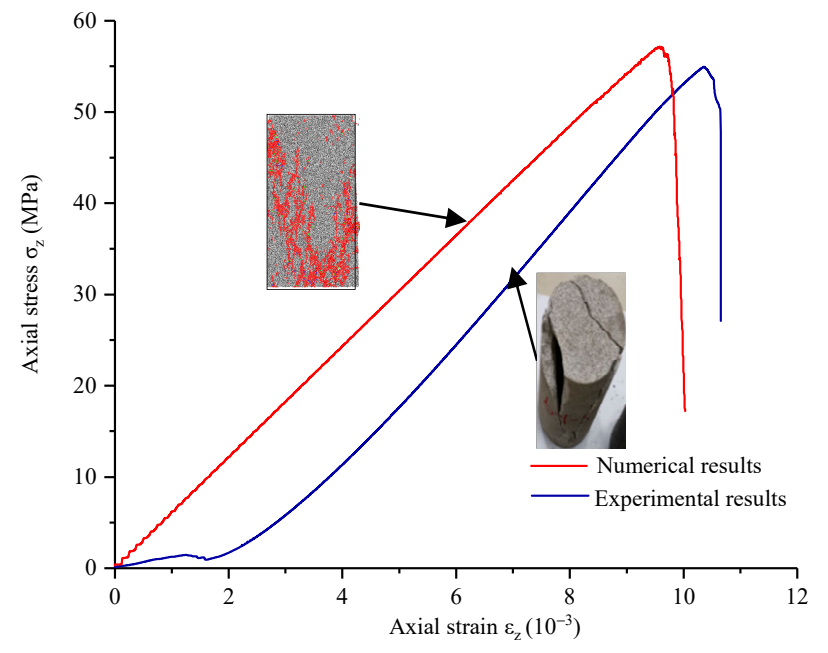

Figure 2. Comparison between the experimental and numerical stress-strain curves and the failure mode of the intact specimen.

\subsection{Model Establishment}

To study the failure characteristics and mechanical properties of specimens with combined of double hole and double fissure defects at different angles, the corresponding model is established. The width $w_{s}$ of the model specimen is $50 \mathrm{~mm}$, the height $h_{s}$ is $100 \mathrm{~mm}$, the distance between the centre of the two holes and the upper and lower boundaries $d_{c h}$ is $25 \mathrm{~mm}$, and the diameter of the holes $r_{h}$ is $10 \mathrm{~mm}$. The width of the two fissures $w_{f}$ is $0.5 \mathrm{~mm}$, and the length $l_{f}$ is $10 \mathrm{~mm}$. The angle between the fissure and horizontal direction is $\alpha$. The values of $\alpha$ are $0^{\circ}, 15^{\circ}, 30^{\circ}, 45^{\circ}, 60^{\circ}, 75^{\circ}$ and $90^{\circ}$. The geometric parameters and numerical model of the specimen are shown in Figure 3. The plane stress model was used in the model. The model was loaded by displacement loading at a rate $v$ of $0.01 \mathrm{~mm} / \mathrm{s}$. 


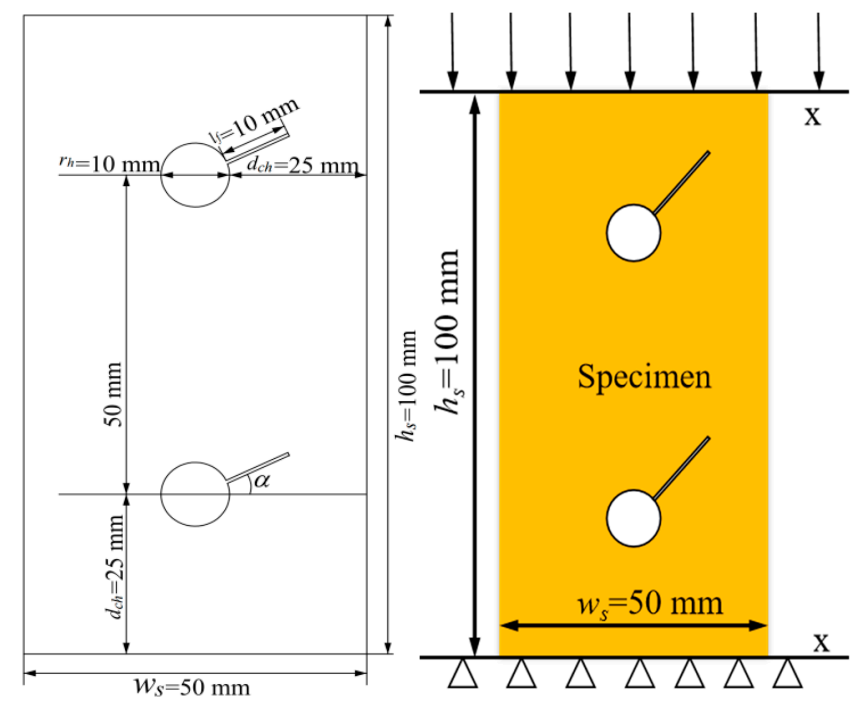

Figure 3. Geometric parameters and numerical model of the specimen.

\section{Analysis of Test Results}

To study the difference in the strength and failure characteristics of the specimens with combined double hole and double fissure defects at different angles $\alpha$ and intact rock samples, the stress $\sigma_{z}$-strain curve $\varepsilon_{z}$, crack initiation stress $\sigma_{c i}$, damage stress $\sigma_{c a}$, peak strength $\sigma_{\max }$, peak strain $\varepsilon_{\max }$ and elastic modulus $E_{i}$ are introduced to analyse the influence of the strength characteristics of the specimens with combined double hole and double fissure defects at different angles. The specific parameter values are shown in Table 3.

Table 3. Experimental mechanical parameters of intact rock and rocks with combined double hole and double fissure defects at different angles.

\begin{tabular}{|c|c|c|c|c|c|c|}
\hline Category & $\sigma_{\max }(\mathrm{MPa})$ & $\varepsilon_{\max }(\mathrm{MPa})$ & $E_{i}(\mathrm{GPa})$ & $\sigma_{c i}(\mathrm{MPa})$ & $\sigma_{c d}(\mathrm{MPa})$ & Number of Cracks \\
\hline Intact rock & 57.16 & 9.22 & 6.28 & 28.70 & 57.06 & 8615 \\
\hline Angle of $90^{\circ}$ & 43.25 & 7.79 & 5.71 & 20.84 & 47.25 & 6824 \\
\hline Angle of $75^{\circ}$ & 43.68 & 8.00 & 5.64 & 17.82 & 43.61 & 6353 \\
\hline Angle of $60^{\circ}$ & 37.77 & 7.14 & 5.45 & 10.37 & 37.77 & 4396 \\
\hline Angle of $45^{\circ}$ & 32.92 & 6.86 & 5.15 & 9.37 & 32.78 & 3713 \\
\hline Angle of $30^{\circ}$ & 32.38 & 6.97 & 4.83 & 9.99 & 32.30 & 5253 \\
\hline Angle of $15^{\circ}$ & 25.84 & 6.25 & 4.68 & 9.55 & 25.83 & 3535 \\
\hline Angle of $0^{\circ}$ & 27.64 & 6.31 & 4.54 & 8.91 & 27.64 & 2891 \\
\hline
\end{tabular}

\subsection{The Stress-Strain Curve of Rock with Combined Holes and Defects}

When the stress $\sigma_{z}$ drops to $30 \%$ of the peak stress, the numerical simulation stops. Compared with the stress-strain $\left(\sigma_{z}-\varepsilon_{z}\right)$ curve of intact rock, the stress-strain $\left(\sigma_{z}-\varepsilon_{z}\right)$ curve of rock with combined double hole and double fissure defects at different angles is almost the same. For all angles, there was an initial compaction, linear elastic deformation, nonlinear deformation and post-peak softening.

The stress-strain $\left(\sigma_{z}-\varepsilon_{z}\right)$ curves and strain-crack $\left(\sigma_{z}-c\right)$ curves of intact rock samples and rocks with combined double hole and double fissure defects at different angles are shown in Figures 4 and 5. It can be seen from the figure that (1) the stress-strain $\left(\sigma_{z}-\mathcal{E}_{z}\right)$ relationships of the intact rock model and defective rock model are approximately linear. Before the peak strength, the samples undergo mainly elastic deformation, and the plastic deformation is smaller. After the peak strength, the stress decreases rapidly, which indicates that the rock has typical brittle failure characteristics. (2) Compared with the numerical model of intact rock, with a decrease in the fissure angle, the elastic stage of the rock with defects and holes is obviously shortened. This shows that the fissure angle is smaller, 
the crack growth rate is faster, and it is easier to cause local damage. (3) Compared with the numerical model of intact rock, the numerical model of rocks with combined double bole and double fissure defects at different angles has a smaller stress reduction rate after the peak stress. These results indicate that holes and cracks weaken the brittleness of the rock and increase its ductility. The above conclusions are consistent with the numerical simulation results of other scholars [40].

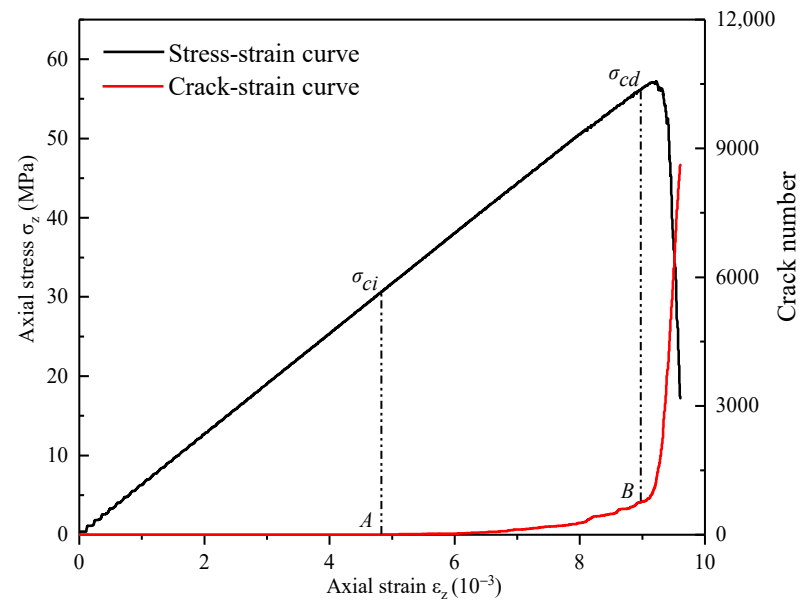

Figure 4. Stress-strain curve of strain cracks for the numerical models of intact rock.

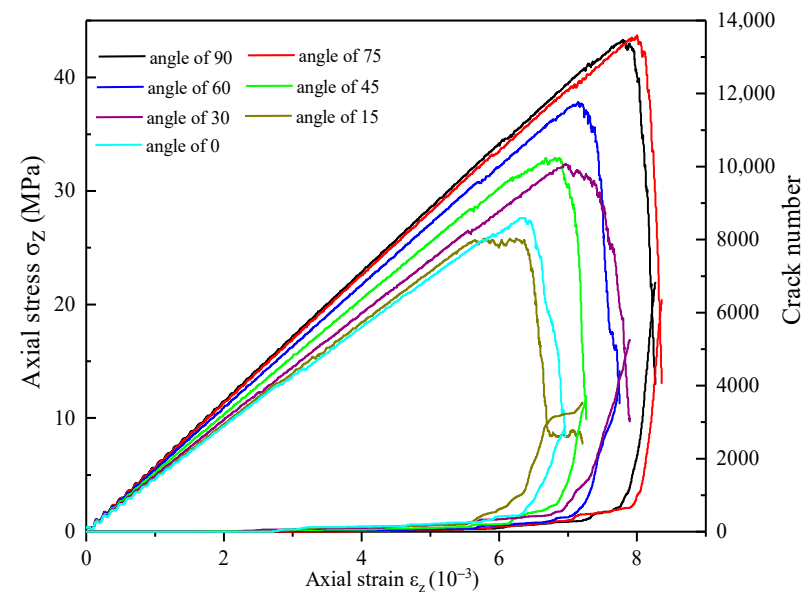

Figure 5. Stress-strain curve of strain cracks for numerical models of rocks with combined double hole and double fissure defects at different angles.

\subsection{Crack Initiation Stress}

During the loading process of the specimen, the contact force between the particles is gradually greater than the bonding force when the rocks are subjected to axial stress, resulting in a local stress concentration in a certain area of the specimen. Micro-cracks and local failure are formed. The axial stress corresponding to the initial generation of microcracks is the crack initiation stress $\left(\sigma_{c i}\right)$.

The change curves of the crack initiation stress $\sigma_{c i}$ of intact rock samples and rocks with combined double hole and double fissure defects at different angles are shown in Figure 6. The figure shows that the crack initiation stress of the intact rock sample is the largest, with a value of $28.70 \mathrm{MPa}$. With a decrease in the fissure angle, the crack initiation stress decreases. When the crack angle changes from $75^{\circ}$ to $60^{\circ}$, the decrease in the crack initiation stress is largest, and the crack initiation stress is reduced from $37.56 \%$ to $63.88 \%$. When the crack angle changes from $60^{\circ}$ to $0^{\circ}$, the overall trend of the crack initiation stress decreases slowly, and the maximum difference is less than $2 \mathrm{MPa}$. 


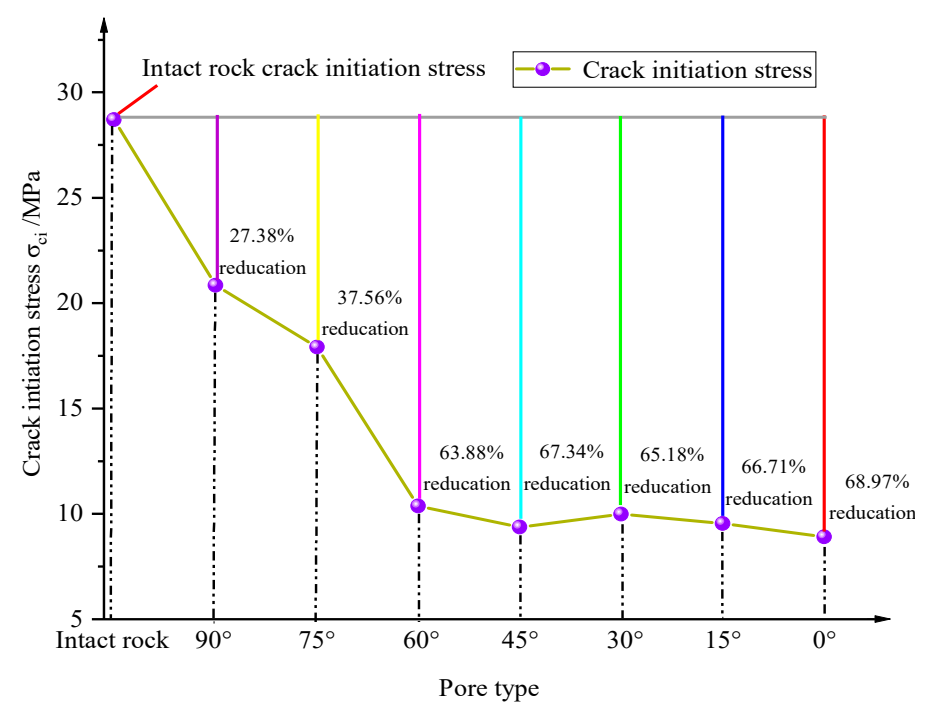

Figure 6. The change curves of crack initiation stress of intact rock samples and rocks with combined double hole and double fissure defects at different angles.

\subsection{Crack Damage Stress}

When the specimen is subjected to axial stress, the specimen begins to produce microcracks locally. With increasing axial stress, the cracks gradually propagate, and the number of cracks increases. When the axial stress further increases to the vicinity of the peak strength, the micro-cracks grow relatively quickly. The stress corresponding to the first inflection point where crack growth is slow is called the crack damage stress $\sigma_{c D}$. The definition of crack damage stress of intact rock $\sigma_{i c D}$ is the same as that of defective rock $\sigma_{d c D}$, both of which are close to the point where the crack number growth rate is the largest. The changes in the damage stress of intact rock samples and rocks with combined double hole and double fissure defects at different angles are shown in Figure 7.

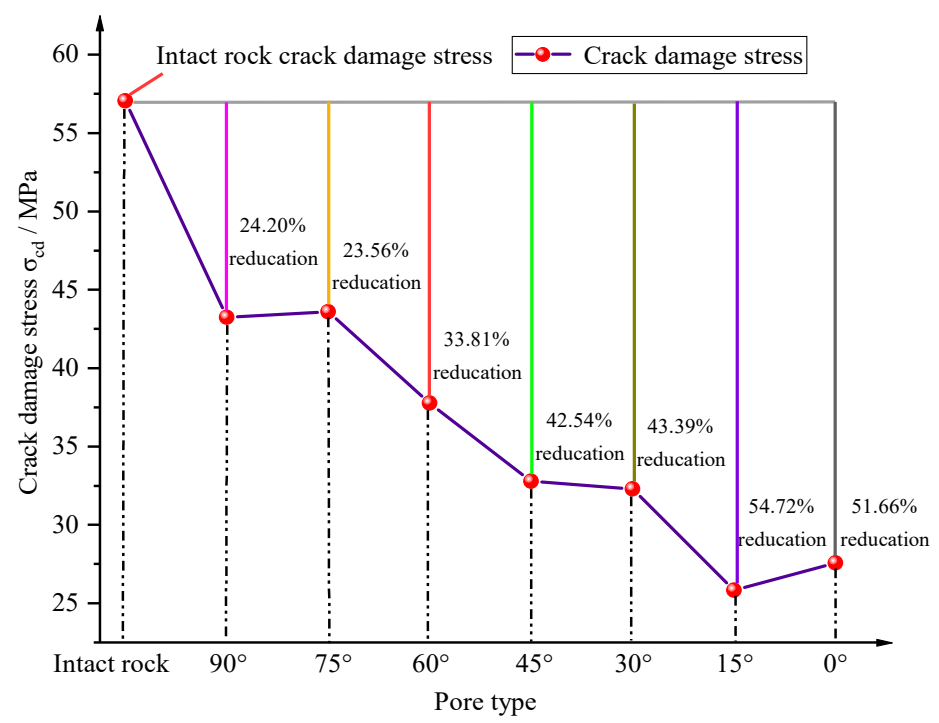

Figure 7. The change curve of the damage stress of intact rock samples and rocks with combined double hole and double fissure defects at different angles.

Figure 7 shows that compared with intact rock samples, the damage stress of the rocks with combined double hole and double fissure defects at different angles is less than that of intact rock. With the decrease in the crack angle, the overall damage stress decreases. When the crack angles change from $90^{\circ}$ to $75^{\circ}$ and from $15^{\circ}$ to $0^{\circ}$, the damage stress increases slightly. When the crack angle changes from $75^{\circ}$ to $60^{\circ}$ and from $60^{\circ}$ to $45^{\circ}$, the damage 
stress continuously decreases, and the slope of decreasing is close. When the crack angle changes from $30^{\circ}$ to $15^{\circ}$, the damage stress decreases greatly. The above phenomenon shows that the crack angles change the degree of rock failure.

\subsection{Elastic Modulus}

The change curves of the elastic modulus of intact rock samples and rocks with combined double hole and double fissure defects at different angles are shown in Figure 8 . Figure 8 shows that, compared with the intact rock sample, with a decrease in the fissure angle, the elastic modulus decreases continuously, and the curve does not show a wave band rise. When the crack angle changes from $90^{\circ}$ to $0^{\circ}$, the decline amplitude of each stage is small, and the maximum is no more than $1.5 \mathrm{GPa}$. When the crack angle changes from $75^{\circ}$ to $60^{\circ}$ and from $60^{\circ}$ to $45^{\circ}$, the damage stress is continuously decreased, and the slope of decreasing is close. When the crack angle changes from $30^{\circ}$ to $15^{\circ}$, the damage stress decreases greatly. The above phenomenon shows that the crack angle changes the degree of rock failure.

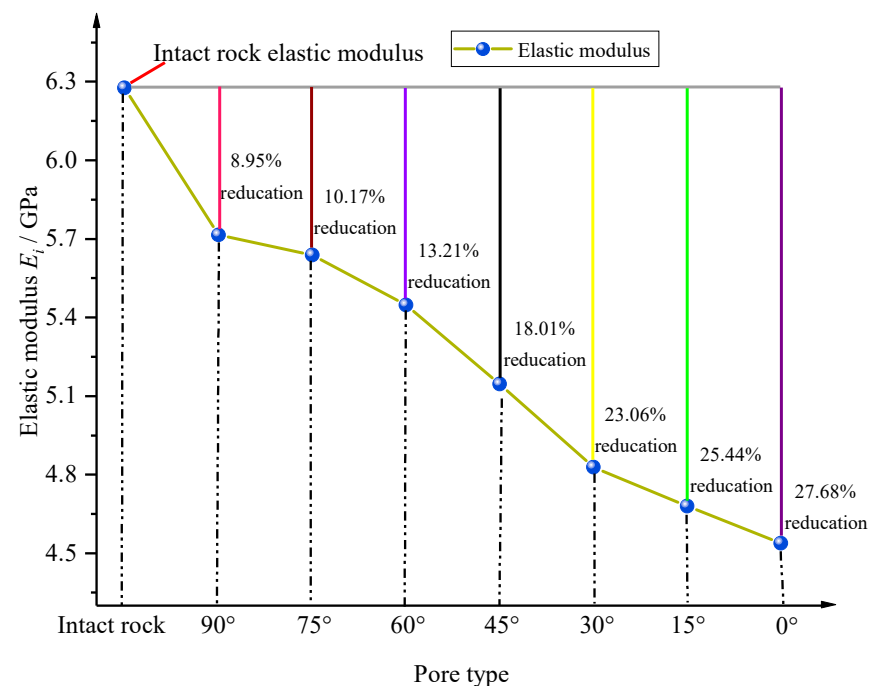

Figure 8. The change curves of the elastic modulus of intact rock samples and rocks with combined double hole and double fissure defects at different angles.

\subsection{Peak Stress}

The peak stress is the maximum stress of the rock in the uniaxial compression test. It represents the maximum strength and bearing capacity of rock, and is an important parameter to study the mechanical properties of rock.

The change curves of the peak stress $\sigma_{\max }$ of intact rock samples and rocks with combined double hole and double fissure defects at different angles are shown in Figure 9. Figure 9 shows that the peak stress curve is almost the same as the damage stress curve. The difference between the damage stress and the peak stress of the intact rock and rock with combined double hole and double fissure defects at different angles is less than $1 \mathrm{MPa}$, which is caused by the brittleness of the simulated sample. During the period of rapid increase in the number of cracks, the compressive strength of the sample reaches the maximum quickly: the strength reaches the peak and begins to drop. 


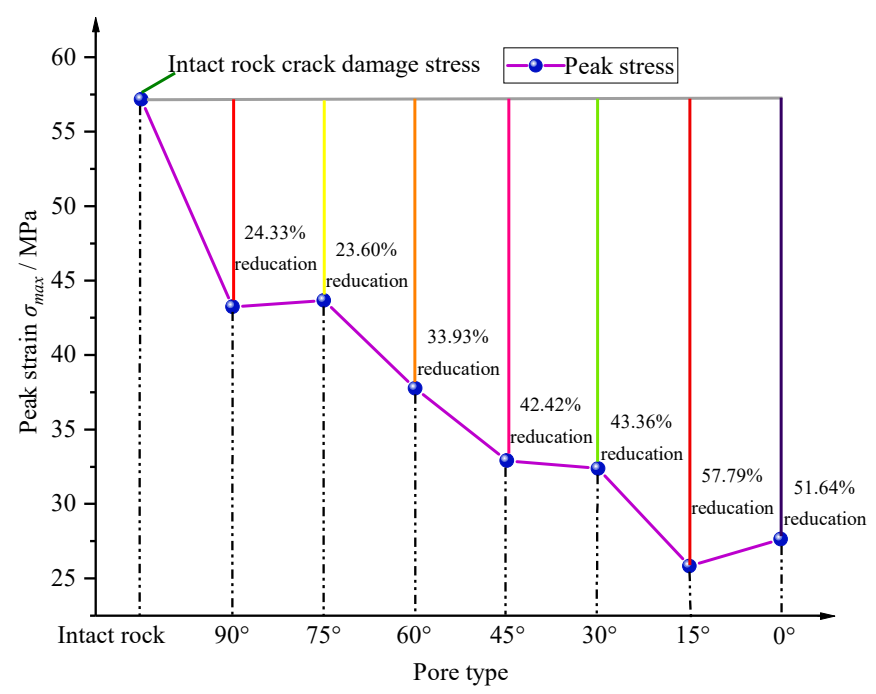

Figure 9. The change curves of the peak stress of intact rock samples and rocks with combined double hole and double fissure defects at different angles.

\subsection{Peak Strain}

The change curves of the peak strain $\varepsilon_{\max }$ of intact rock samples and rocks with combined double hole and double fissure defects at different angles are shown in Figure 10. Figure 10 shows that compared with the intact rock samples, the peak strain of the rock with the combined double hole and double fissure defects at different angles is smaller. With the decrease in the crack angle, the peak strain shows a downward trend. When the crack angle changes from $90^{\circ}$ to $75^{\circ}$ and from $15^{\circ}$ to $0^{\circ}$, the peak strain increases slightly. The results show that the generation of cracks in rock samples reduces the peak strain during compression. When the fissure angle decreases, the crack length corresponding to the horizontal direction is longer. The deformation space is larger.

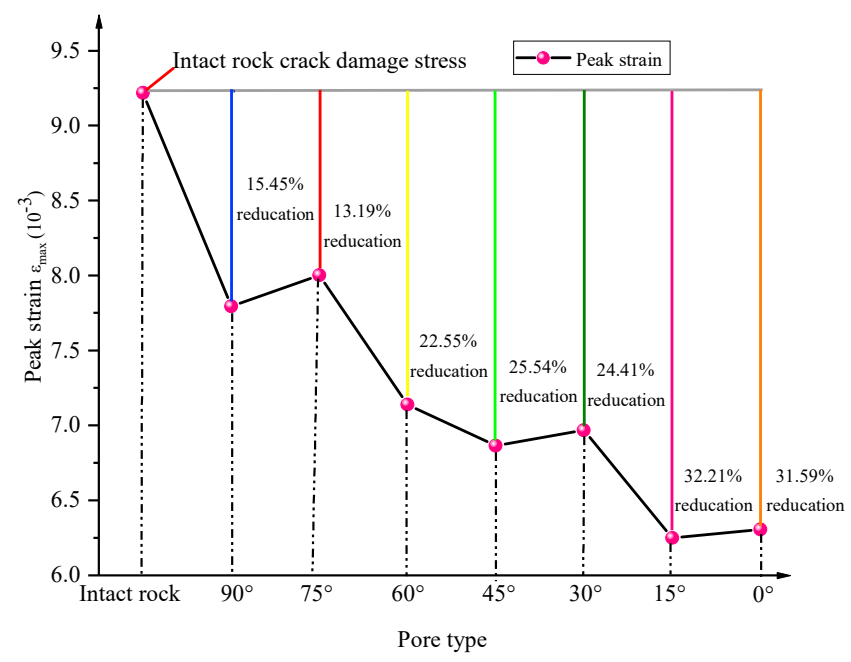

Figure 10. The change curves of the peak strain of intact rock samples and rocks with combined double hole and double fissure defects at different angles.

\section{Failure Characteristics and Stress Evolution of Specimens}

4.1. Analysis of the Failure Characteristics of Rock with Combined Double Hole and Double Fissure Defects at Different Angles

To study the failure characteristics and fissure development process of intact rock and rocks with combined double hole and double fissure defects at different angles, the initiation, damage, peak value and final failure time of the samples are selected as characteristic times for comparison. The macro failure modes of intact rock and rocks with 
combined double hole and double fissure defects at different angles are shown in Figure 11. Apparently, the cracks of intact rock and rock with combined double hole and double fissure defects at different angles are mainly tensile cracks, and there are relatively few shear cracks. (In the process of failure, red indicates tension cracks, blue indicates compression shear cracks, and green indicates tension shear cracks).
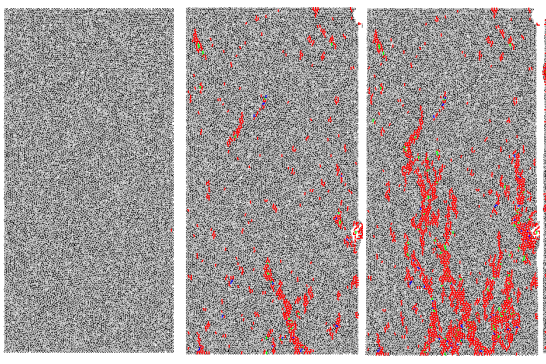

(a) Intact rock
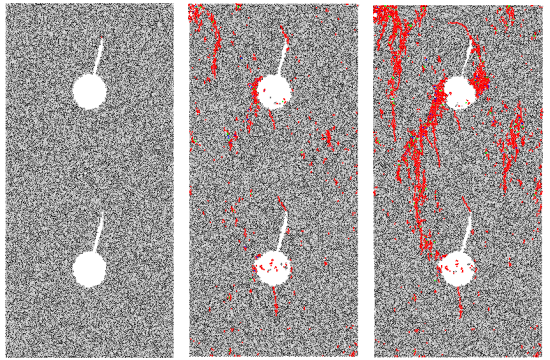

(c) Angle of $75^{\circ}$
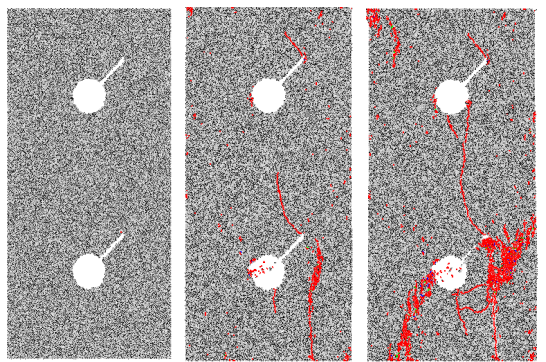

(e) Angle of $45^{\circ}$
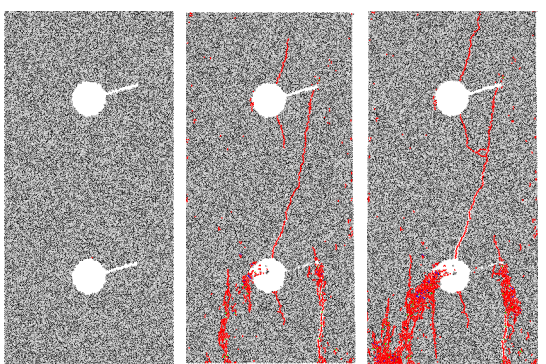

(g) Angle of $15^{\circ}$
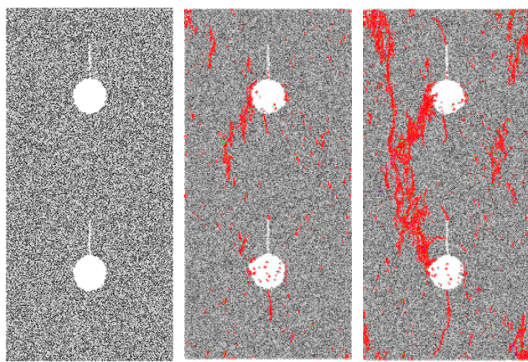

(b) Angle of $90^{\circ}$
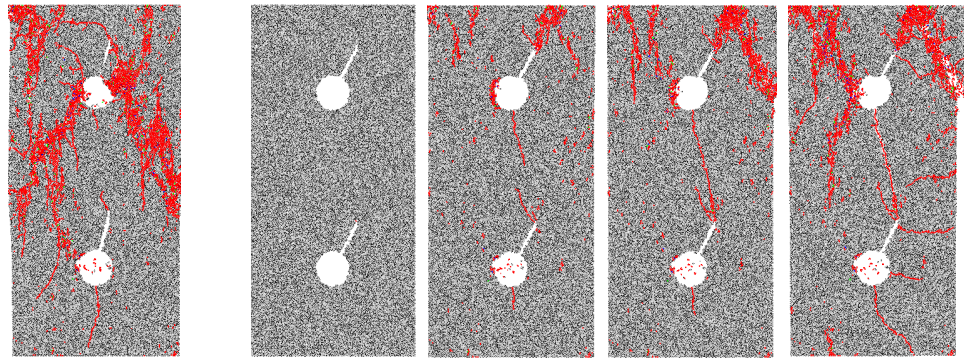

(d) Angle of $60^{\circ}$
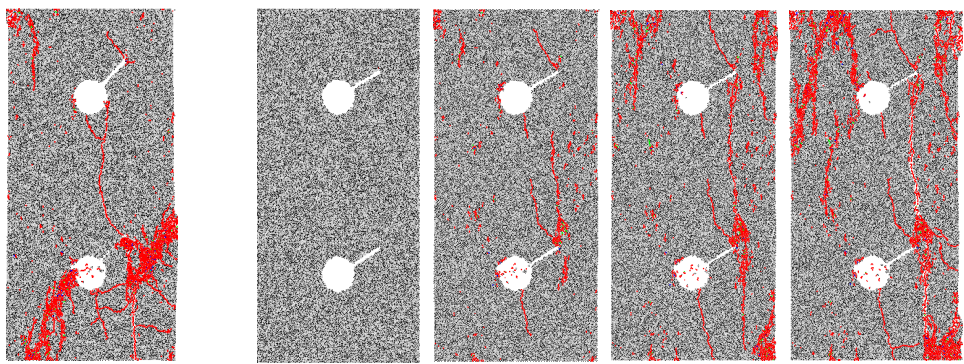

(f) Angle of $30^{\circ}$
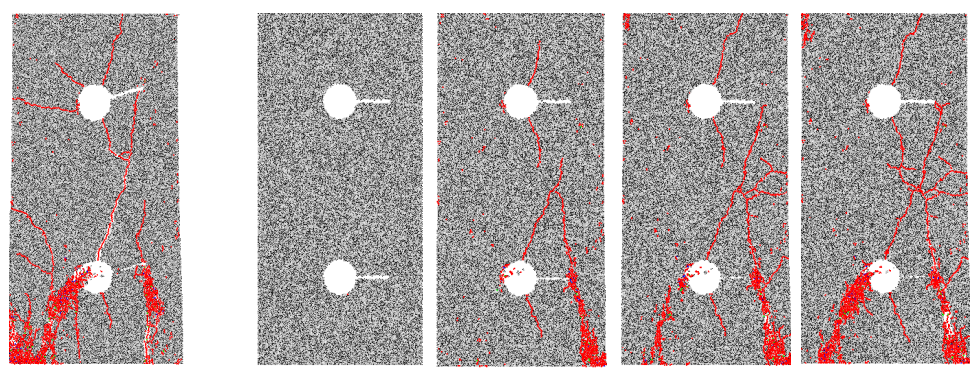

(h) Angle of $0^{\circ}$

Figure 11. The macro failure modes of intact rock and rocks with combined double hole and double fissure defects at different angles.

The failure process of the intact rock shows that the fracture of the intact rock model is mainly concentrated in the lower end of the specimen, and the crack propagation path extends from one side to both sides. When the crack penetrates from the bottom to the upper left corner, transient slip deformation occurs. Many tensile shear cracks are formed 
in this process. Finally, a V-shaped fracture mode is formed, and the failure mode is mainly tensile failure and a little shear failure.

When the crack angles are $90^{\circ}$ and $75^{\circ}$, rocks with combined hole and fissure defects begin to produce cracks appearing at the bottom and tip of the two circular holes. With the increase in the axial stress, cracks appear rapidly at the side ends of the two circular holes and begin to propagate until penetrating, and the cracks begin to develop rapidly towards the boundary of the model, producing a sliding surface and forming tensile shear and compressive shear. However, there is no connecting line between the lower combined hole and fissure defect and the upper combined hole and fissure defect. Finally, the fracture modes are V-shaped and inverted V-shaped, and the failure modes are mainly shear failure and slight tensile failure.

When the crack angles are $60^{\circ}$ and $45^{\circ}$, rocks with combined hole and fissure defects begin to produce cracks appearing at the tip of the specimen. With the increase in the axial stress, the crack tip extends to the boundary, forming a failure concentration area and connecting to the right boundary, forming a local slip of the boundary and producing a local compression shear crack. The crack at the bottom of the lower crack tip and the bottom of the upper circular hole expands until connecting. Finally, the failure mode of the model is T-shaped and inverted T-shaped, and the upper and lower holes and cracks combine to form through cracks. The failure mode is mainly tension and slight shear failure.

When the crack angle is $30^{\circ}$, rocks with combined hole and fissure defects begin to produce cracks at the crack tip and the bottom of the circular hole. With increasing axial stress, the combined hole and fissure defects develop cracks on both sides: the crack tip first penetrates and develops to both sides of the boundary, and the cracks at both ends of the top also begin to expand downward to both sides of the model. The final failure mode of the model is the "II" type, the upper and lower groups of holes and fissures form through cracks, and the failure mode is tension dominated.

When the crack angles are $15^{\circ}$ and $0^{\circ}$, rocks with combined hole and fissure defects begin to produce cracks appearing at the upper and lower sides of the round hole. With increasing axial stress, the cracks of the lower circular hole develop and connect to the top of the crack and expand to the bottom at both ends. The concentrated failure area of the cracks appears along the side end of the lower circular hole and the crack tip. The final failure mode of the model is the " $\mathrm{X}$ " type, and the upper and lower groups of combined hole and fissure defects form through fractures. The failure mode is mainly tension and slight shear failure.

From the above analysis and compared with the intact rock failure mode, it is evident that the failure mode and failure degree of the rock with combined double hole and double fissure defects at different angles are different. Figure 12 shows that the number of cracks in intact rock is much greater than that in rock with combined double hole and double fissure defects at different angles, and the number of cracks decreases with decreasing crack angle. For actual geotechnical engineering, prefabricating horizontal holes and fissures should be considered to reduce the number of fissures to control the degree of rock failure. 


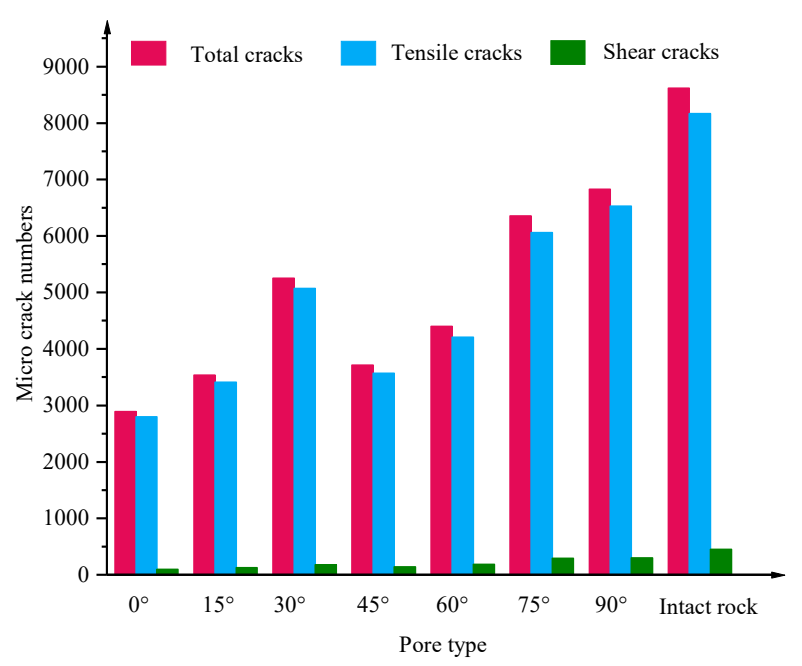

Figure 12. Final total number of cracks after failure.

\subsection{Analysis of Force Chain Contact and Stress Evolution Results}

To study the stress distribution and evolution results of intact rock and rock with combined double hole and double fissure defects at different angles, the contact force chain and stress evolution results of different types of models are analysed. The contact force chain diagram and stress evolution results of the model of intact rock and rock with combined double hole and double fissure defects at different angles are shown in Figure 13. In the contact force chain diagram, the red circle represents the tensile stress area, and the black area represents the compressive stress area. In the stress evolution diagram, the tensile stress is positive, and the compressive stress is negative.

Figure 13 shows that the failure of the numerical model of intact rock and rock with combined double hole and double fissure defects at different angles results in the concentration of compressive stress and tensile stress, and there are more stress concentration areas in the intact rock model. It can be seen from the Figure 13 that there are three tensile stress concentration areas for the intact rock, and the maximum stress value reaches $16 \mathrm{MPa}$; There are four compressive stress concentration areas, and the maximum stress is $10 \mathrm{MPa}$. With the decrease of fracture angle, the degree of stress concentration decreases. When the specimen fracture angle is $45^{\circ}$, there are two tensile stress concentration areas, and the maximum stress is $10 \mathrm{MPa}$; There are two compressive stress concentration areas, and the maximum stress is $6 \mathrm{MPa}$. When the specimen fracture angle is $0^{\circ}$, there are two tensile stress concentration areas, the maximum stress is $5 \mathrm{MPa}$ and the stress at the edge of the specimen is $8 \mathrm{MPa}$. There are three compressive stress concentration areas, and the maximum stress of specimen is $3 \mathrm{MPa}$. The decrease of fracture angle weakens the stress concentration, which indicates that the decrease in the crack angle makes the model stress release space larger, the stress is released earlier in the compression process, and the bearing and compression capacity of the rock is reduced. Both the intact rock model and the defective rock model are destroyed mainly by the compressive stress, which is greater than the tensile stress and is also the reason why the tensile stress concentration is not obvious in the force chain diagram.

From the point of view of the stress concentration area, in the numerical model of rock with combined hole and fissure defects, the stress concentration area appears around the hole fracture or on the line that connects the two defect combinations, which is also the largest area of stress concentration in the defect rock. This result shows that the rock defects determine the crack growth and stress release direction in the process of compression. 

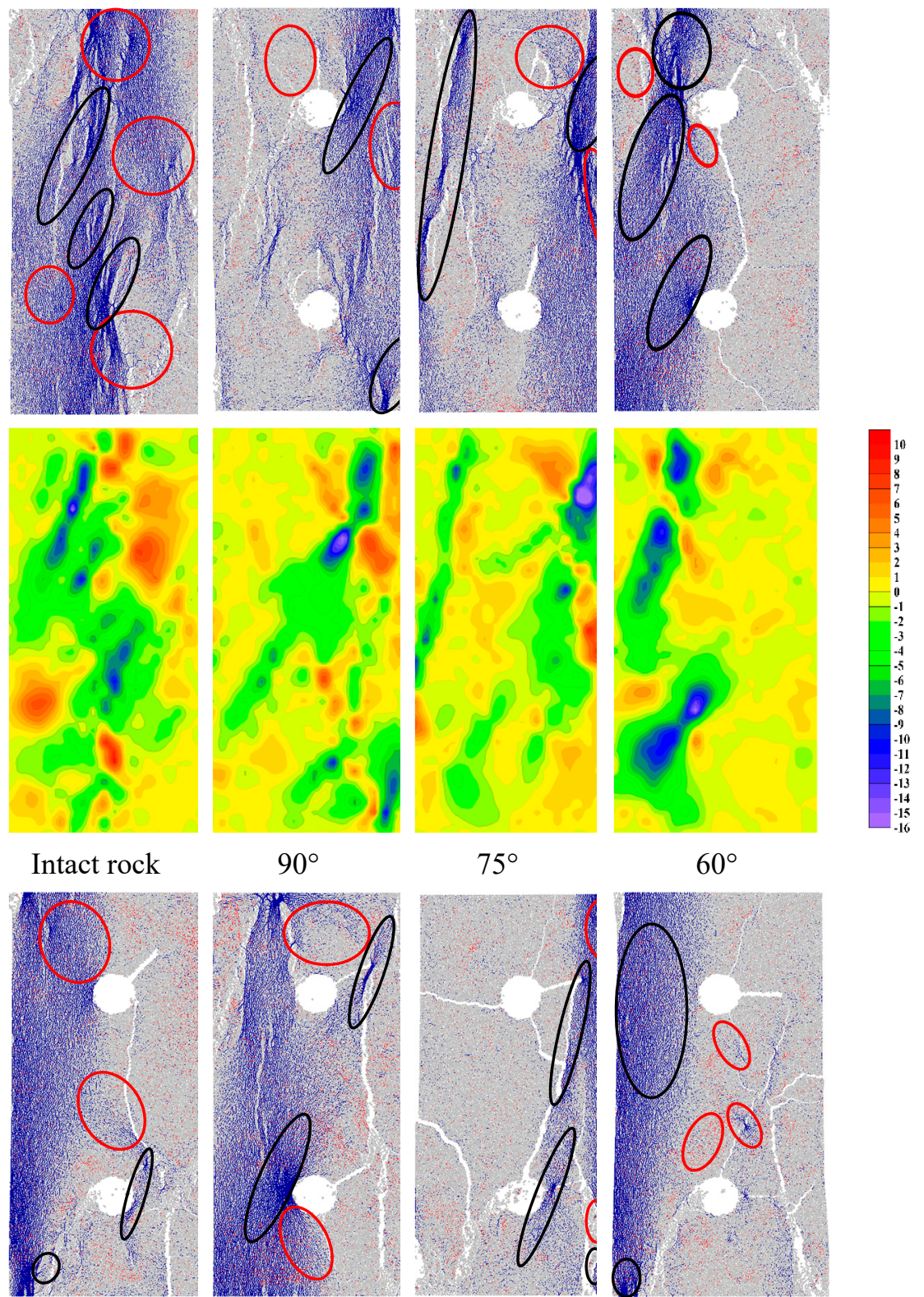

$90^{\circ}$

$75^{\circ}$

$60^{\circ}$
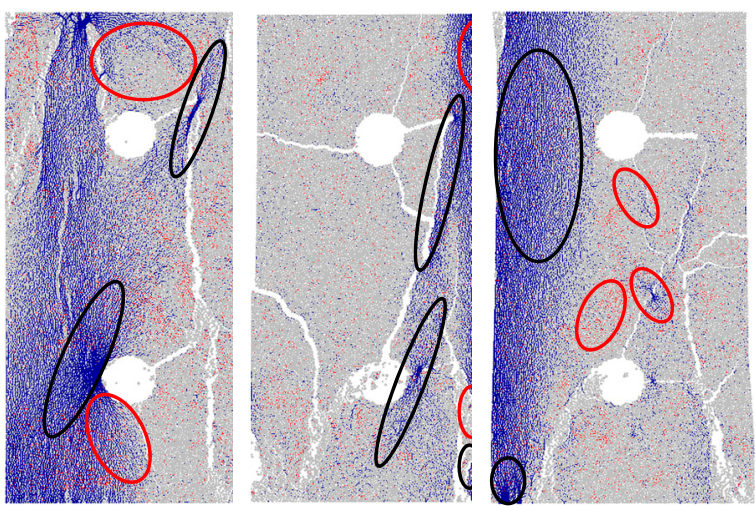

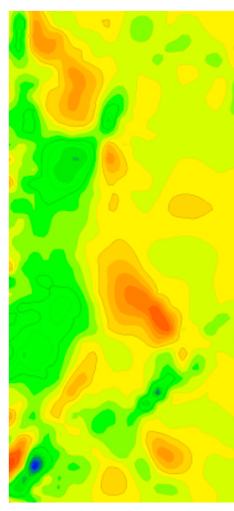

$45^{\circ}$

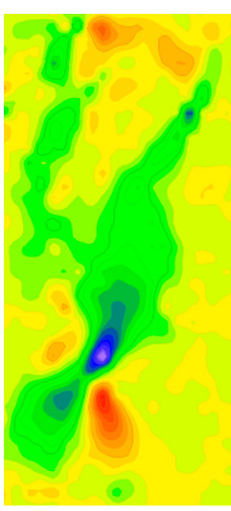

$30^{\circ}$

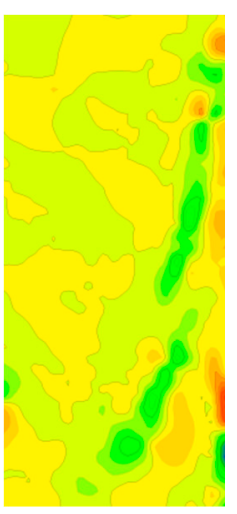

$15^{\circ}$

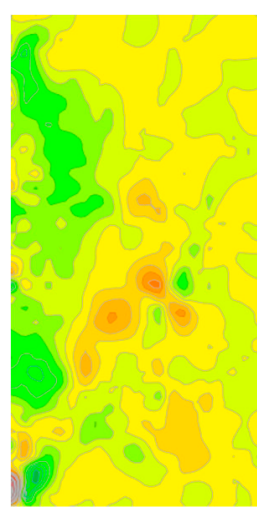

$0^{\circ}$

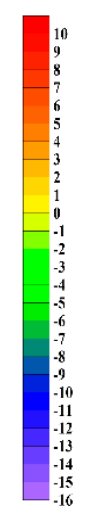

Figure 13. Contact force chain and stress evolution results of intact rock and rock with combined double hole and double fissure defects at different angles. 


\section{Conclusions}

In this paper, uniaxial compression tests are carried out on rock samples with combined double hole and double fissure defects using particle flow numerical simulation software (PFC2D). The conclusions are as follows:

(1) Compared with intact rock, rock with combined double hole and double fissure defects at different angles reduces the mechanical properties of the rock and weakens the brittleness of the rock. Moreover, with the decrease in the crack angle, the crack initiation stress, damage stress, elastic modulus and peak stress of the defective rock show a downward trend, while the peak strain shows an upward trend.

(2) The failure characteristics of the rock samples are significantly affected by the combined hole and fracture defects. The different crack angles in the specimens lead to different failure modes, resulting in different crack initiation positions and crack growth spaces.

(3) After numerical simulation, compressive stress and tensile stress concentrations areas appear in the rock model, and stress concentration areas appear along the line that connects the defect combinations. With a decrease in the fracture angle, the stress concentration area decreases.

(4) Numerical simulation research on rock with combined double hole and double fissure defects at different angles can provide scientific guidance for the pressure relief of coal mine boreholes and can help reduce the damage caused by prefabricated defects in geotechnical engineering.

Author Contributions: Conceptualization, N.J.; methodology, N.J.; software, J.M.; validation, X.W., X.J. and J.M.; data curation, D.Y.; writing-original draft preparation, J.M.; writing-review and editing, J.M. and N.J.; funding acquisition, N.J. All authors have read and agreed to the published version of the manuscript.

Funding: This work was supported by National Key R\&D Program (2018YFC0604705); National Natural Science Foundation of China (52004146, 51904167, 51774194); Taishan Scholar Talent Team Support Plan for Advantaged \& Unique Discipline Areas; SDUST Research Fund (2019TDJH101); Scientific Research Foundation of Shandong University of Science and Technology for Recruited Talents (2019RCJJ019) and Natural Science Fundation Youth Branch of Shandong Province (ZR2020QE102, ZR2020QE129).

Institutional Review Board Statement: Not applicable.

Informed Consent Statement: Not applicable.

Data Availability Statement: The data are available and explained in this article; readers can access the data supporting the conclusions of this study.

Conflicts of Interest: The authors declare no conflict of interest.

\section{References}

1. Rego, F.B.; Mehrabi, M.; Sanaei, A.; Sepehrnoori, K. Improvements on modelling wettability alteration by engineered water injection: Surface complexation at the oil/brine/rock contact. Fuel 2021, 284, 118991. [CrossRef]

2. Sun, J.; Takahashi, Y.; Strosnider, W.H.J.; Kogure, T.; Dong, Z. Identification and quantification of contributions to karst groundwater using a triple stable isotope labeling and mass balance model. Chemosphere 2020, 263, 127946. [CrossRef] [PubMed]

3. Dong, W.; Wu, Z.M.; Zhou, X.M.; Wang, N.; Kastiukas, G. Thermal jet drilling of granite rock: A numerical 3D finite-element study. An experimental study on crack propagation at rock-concrete interface using digital image corrlelation technique. Eng. Fract. Mech. 2017, 171, 50-63. [CrossRef]

4. Gnos, E.; Mullis, J.; Ricchi, E.; Bergemann, C.; Janots, E.; Berger, A. Episodes of fissure formation in the Alps: Connecting quartz fluid inclusion, fissure monazite age, and fissure orientation data. Swiss J. Geosci. 2021, 114, 14. [CrossRef]

5. Al-Bazali, T.; Zhang, J.; Chenevert, M.E.; Sharma, M. Experimental and numerical study on the impact of strain rate on failure characteristics of shales. J. Pet. Sci. Eng. 2015, 60, 194-204. [CrossRef]

6. $\quad$ Feng, F.; Chen, S.J.; Wang, Y.J.; Huang, W.P.; Han, Z.Y. Cracking mechanism and strength criteria evaluation of granite affected by intermediate principal stresses subjected to unloading stress state. Int. J. Rock. Mech. Min. 2021. [CrossRef]

7. Yang, H.Q.; Zhang, N.; Han, C.L.; Sun, C.L.; Song, G.H.; Sun, Y.N.; Sun, K. Stability control of deep coal roadway under the pressure relief effect of adjacent roadway with large deformation: A case study. Sustainability 2021, 13, 4412. [CrossRef] 
8. Zhang, S.C.; Li, Y.Y.; Liu, H.; Ma, X.W. Experimental investigation of crack propagation behavior and failure characteristics of cement infilled rock. Constr. Build. Mater. 2021, 268, 121735. [CrossRef]

9. Cui, Z.; Sheng, Q.; Luo, Q.Z.; Zhang, G.M. Investigating the anisotropy of mechanical parameters of schist rock with practical numerical methods. Sustainability 2021, 13, 725. [CrossRef]

10. Shi, G.C.; Gu, G.K.; Zhou, H.; Tao, Z.G.; Pan, H.Y.; Tang, T. Stability monitoring and analysis of high and steep slope of a hydropower station. Geofluids 2020, 8840269.

11. Sun, Y.T.; Li, G.C.; Zhang, J.F.; Xu, J.H. Failure mechanisms of rheological coal roadway. Sustainability 2020, 12, 2885. [CrossRef]

12. Park, K.; Lee, B.; Lee, K.; Kim, D. Analysis of effects of rock physical properties changes from freeze-thaw weathering in Ny-Angstrom lesund region: Part 2-correlations and prediction of weathered properties. Appl. Sci. 2020, 10, 1707. [CrossRef]

13. Caselle, C.; Bonetto, S.; Comina, C.; Stocco, S. GPR surveys for the prevention of karst risk in underground gypsum quarries. Tunn. Undergr. Space Technol. 2020, 95, 103137. [CrossRef]

14. Wang, L.F.; Zhou, X.P. A field-enriched finite element method for simulating the failure process of rocks with different defects. Comput. Struct. 2021, 250, 106539. [CrossRef]

15. Feng, F.; Li, X.B.; Rostami, J.; Peng, D.X.; Li, D.Y.; Du, K. Numerical investigation of hard rock strength and fracturing under polyaxial compression based on Mogi-Coulomb failure criterion. Int. J. Geomech. 2019, 19, 04019005. [CrossRef]

16. Jiang, N.; Yin, D.W.; Ma, J.B.; Han, L.; Pan, H.Y.; Yin, Q. Effects of water immersion on the long-term bearing characteristics of crushed gangue in goaf. Geofluids 2021. [CrossRef]

17. Fleetwood, B.; Brook, M.; Brick, G.; Richards, N.; Adam, L.; Black, P. Characterization of a highly heterogeneous flysch deposit and excavation implications: Case study from Auckland, New Zealand. Bull. Eng. Geol. Environ. 2020, 79, 4565-4578. [CrossRef]

18. Wu, T.H.; Gao, Y.T.; Zhou, Y.; Li, J.W. Experimental and numerical study on the interaction between holes and fissures in rock-like materials under uniaxial compression. Theor. Appl. Fract. Mech. 2020, 106, 102488. [CrossRef]

19. Clark, M.; Day, J. Mineralogical and sample selection implications for geomechanical properties of intact heterogeneous and veined rocks from the Legacy skarn deposit. Eng. Geol. 2021, 285, 106067. [CrossRef]

20. Jiang, N.; Wang, C.X.; Pan, H.Y.; Yin, D.W.; Ma, J.B. Modeling study on the influence of the strip filling mining sequence on mining-induced failure. Energy Sci. Eng. 2020, 8, 2239-2255. [CrossRef]

21. Xia, Z.G.; Jiang, N.; Yang, H.S.; Han, L.; Pan, H.Y.; Zhao, Z.H.; Feng, Q.L. Effect of Multiple Hole Distribution and Shape Based on Particle Flow on Rocklike Failure Characteristics and Mechanical Behavior. Adv. Civ. Eng. 2020, 2020, 8822225.

22. Zhao, B.; Zhu, G.Y.; Shang, Y.J.; Zhang, H. Predicting collapse depth of paleocaves in carbonate reservoirs. Carbonates Evaporites 2021, 36, 27. [CrossRef]

23. Chen, W.; Wan, W.; Zhao, Y.L.; Peng, W.Q. Experimental study of the crack predominance of rock-like material containing parallel double fissures under uniaxial compression. Sustainability 2020, 12, 5188. [CrossRef]

24. Chen, S.J.; Xia, Z.G.; Feng, F.; Yin, D.W. Numerical study on strength and failure characteristics of rock samples with different hole defects. Bull. Eng. Geol. Environ. 2020, 7, 1-18. [CrossRef]

25. Wang, Y.X.; Zhang, H.; Lin, H.; Zhao, Y.L.; Li, X.; Liu, Y. Mechanical behavior and failure analysis of fracture-filled gneissic granite under uniaxial compression. Theor. Appl. Fract. Mech. 2020, 108, 102674. [CrossRef]

26. Wang, C.L.; Zhao, Y.; Zhao, Y.L.; Wen, W. Study on the interaction of collinear cracks and wing cracks and cracking behavior of rock under uniaxial compression. Adv. Civ. Eng. 2018, 2018, 5459307. [CrossRef]

27. Zeng, W.; Yang, S.Q.; Tian, W.L. Experimental and numerical investigation of brittle sandstone specimens containing different shapes of holes under uniaxial compression. Eng. Fract. Mech. 2018, 200, 430-450. [CrossRef]

28. Zhu, D.; Jiang, H.W.; Yin, Q.; Zong, Y.J.; Tao, X.L. Experimental study on mechanical characteristics of sandstone containing arc fissures. Arabian J. Geosci. 2018, 11, 637. [CrossRef]

29. Huang, Y.H.; Yang, S.Q.; Ranjith, P.G.; Zhao, J. Strength failure behavior and crack evolution mechanism of granite containing pre-existing non-coplanar holes: Experimental study and particle flow modeling. Comput. Geotech. 2017, 88, 182-198. [CrossRef]

30. Huang, Y.H.; Yang, S.Q.; Zeng, W. Experimental and numerical study on loading rate effects of rock-like material specimens containing two unparallel fissures. J. Cent. South Univ. 2016, 23, 1474-1485. [CrossRef]

31. Chen, M.L.; Jing, H.W.; Ma, X.J.; Su, H.J.; Du, M.R.; Zhu, T.T. Fracture evolution characteristics of sandstone containing double fissures and a single circular hole under uniaxial compression. Int. J. Min. Sci. Technol. 2017, 27, 499-505. [CrossRef]

32. Liu, X.R.; Yang, S.Q.; Huang, Y.H.; Cheng, J.L. Experimental study on the strength and fracture mechanism of sandstone containing elliptical holes and fissures under uniaxial compression. Eng. Fract. Mech. 2019, 205, 205-217. [CrossRef]

33. Yin, Q.; Jing, H.W.; Su, H.J. Investigation on mechanical behavior and crack coalescence of sandstone specimens containing fissure-hole combined flaws under uniaxial compression. Geosci. J. 2018, 22, 825-842. [CrossRef]

34. Cundall, P.A.; Strack, O.D. A discreate particle model for granula assemblies. Geotachnique 1979, 29, 47-65. [CrossRef]

35. Cho, N.; Martin, C.D.; Sego, D.C. A clumped particle model for rock. Int. J. Rock. Mech. Min. 2007, 44, 997-1010. [CrossRef]

36. Lisjak, A.; Grasselli, G. A review of discrete modeling techniques for fracturing processes in discontinuous rock masses. J. Rock Mech. Geotech. 2014, 6, 301-314. [CrossRef]

37. Yang, S.Q.; Yang, Z.; Zhang, P.C.; Tan, W.L. Experiment and peridynamic simulation on cracking behavior of red sandstone containing a single non-straight fissure under uniaxial compression. Theor. Appl. Fract. Mech. 2020, 108, 102637. [CrossRef]

38. Yang, S.Q.; Jing, H.W.; Xu, T. Mechanical behavior and failure analysis of brittle sandstone specimens containing combined flaws under uniaxial compression. J. Cent. South Univ. 2014, 21, 2059-2073. [CrossRef] 
39. Zhao, Y.S.; Gao, Y.T.; Wu, S.C. Experimental and Numerical Studies of Brittle Rock-Like Samples with Internal Open Fractures and Cavities Under Uniaxial Compression. Arabian J. Sci. Eng. 2020, 45, 8349-8368. [CrossRef]

40. Chen, M.; Liu, J.; Xie, Z.Y.; Liu, J.J.; Hu, X.J.; Li, B.Y.; Cen, Y. Discrete element modeling on mechanical behavior of heterogeneous rock containing X-shaped fissure under uniaxial compression. Geofluids 2020. [CrossRef] 